\title{
Hypothermic Preservation of Rat Hearts Using Antifreeze Glycoprotein
}

\author{
Shintaro TAKAGO $^{1}$, Isao MATSUMOTO ${ }^{1}$, Hiroki KATO ${ }^{1}$, Naoki SAITO ${ }^{1}$, Hideyasu \\ UEDA $^{1}$, Kenji IINO ${ }^{1}$, Keiichi KIMURA ${ }^{1}$, Hirofumi TAKEMURA ${ }^{1}$ \\ ${ }^{1}$ Department of Cardiovascular Surgery, Kanazawa University, Kanazawa, Ishikawa, Japan
}

Received March 28, 2020

Accepted September 28, 2020

Epub Ahead of Print November 25, 2020

\section{Summary}

Antifreeze proteins are an effective additive for low-temperature preservation of solid organs. Here, we compared static hypothermic preservation with and without antifreeze glycoprotein (AFGP), followed by nonfreezing cryopreservation of rat hearts. The heart was surgically extracted and immersed in one of the cardioplegia solutions after cardiac arrest. Control rat hearts $(n=6)$ were immersed in University of Wisconsin (UW) solution whereas AFGP-treated hearts (AFGP group) $(n=6)$ were immersed in UW solution containing $500 \mu \mathrm{g} / \mathrm{ml}$ AFGP. After static hypothermic preservation, a Langendorff apparatus was used to reperfuse the coronary arteries with oxygenated Krebs-Henseleit solution. After 30, 60, 90, and $120 \mathrm{~min}$, the heart rate (HR), coronary flow (CF), cardiac contractile force (max $\mathrm{dP} / \mathrm{dt}$ ), and cardiac diastolic force $(\mathrm{min} \mathrm{dP} / \mathrm{dt}$ ) were measured. Tissue water content (TWC) and tissue adenosine triphosphate (ATP) levels in the reperfused preserved hearts were also assessed. All the parameters were compared between the control and AFGP groups. Compared with the control group, the AFGP group had significantly $(p<0.05)$ higher values of the following parameters: $\mathrm{HR}$ at 60,90 , and $120 \mathrm{~min}$; CF at all four time points; max dP/dt at $90 \mathrm{~min}$; min dP/dt at 90 and $120 \mathrm{~min}$; and tissue ATP levels at $120 \mathrm{~min}$. TWC did not differ significantly between the groups. The higher HR, CF, max dP/dt, min dP/dt, and tissue ATP levels in the AFGP compared with those in control hearts suggested that AFGP conferred superior hemodynamic and metabolic functions. Thus, AFGP might be a useful additive for the static/nonfreezing hypothermic preservation of hearts.

\section{Key words}

Antifreeze glycoprotein $\bullet$ Hypothermic preservation • Rat

\section{Corresponding author}

Shintaro Takago, Department of Cardiovascular Surgery, Kanazawa University 13-1 Takara-machi, Kanazawa, Ishikawa, 920-8641, Japan. E-mail: shintaro-takago@med.kanazawau.ac.jp

\section{Introduction}

Heart transplantation is an established treatment for end-stage heart failure. Methods used to preserve donor hearts are broadly classified as coronary perfusion preservation and static hypothermic preservation. Coronary perfusion is effective in extending the ischemic time, but requires specialized circuits and devices (Michel et al. 2015). Thus, owing to its ease of use and low cost, static hypothermic preservation has become the standard method for heart preservation in cases of heart transplantation.

Static hypothermic preservation of organs reduces metabolic processes of the preserved organ and is thought to be effective for preservation at lower temperatures (Belzer and Southard 1988). However, cryopreservation methods can lead to low-temperature injuries, such as electrolyte imbalances and cellular edema (Jahania et al. 1999). With constant improvements in the therapeutic outcomes of heart transplantations, reducing the preservation time of the donor heart is considered very important because, when the preservation time of the donor heart exceeds $200 \mathrm{~min}$, the long-term outcome is poor (Stehlik et al. 2011). Two problems associated with static hypothermic preservation are lowtemperature injury and time constraints. Approaches to

PHYSIOLOGICAL RESEARCH • ISSN 1802-9973 (online) 
overcome these problems would make it easier to transport donor hearts over long distances.

In 1969, antifreeze proteins (AFPs) were discovered in fish of the Nototheniidae family, which are native to the Antarctic Ocean. In the low temperatures of the Antarctic Ocean, fish are constantly in danger of their blood freezing. However, the AFPs produced in their bodies lower the freezing point of their blood and inhibit the growth of ice crystals. AFPs are classified as AFPs I-IV and antifreeze glycoproteins (AFGPs) (Harding et al. 2003). Besides their ability to lower the freezing point of body fluids, other effects of AFPs in hypothermic environments include cell preservation via interruption of cell membrane ion channels, and stabilization of the cell membrane (Rubinsky et al. 1990) (Rubinsky et al.1992).

In recent years, studies on large-scale purification of AFPs have been carried out, pioneering their practical applications (Nishimiya et al. 2008). As a result, the focus of research has expanded to include high-purity refinement of AFGP (Burcham et al. 2006). It has further been reported that AFGP is effective as a cryoprotectant for the hypothermic storage of islet and sperm cells (Matsumoto et al. 2006, Qadeer et al. 2015). However, these reports have focused on cell preservation. Thus, the effectiveness of AFGP as a cryoprotectant for solid organ storage has yet to be established. In the present study, we evaluated the effectiveness of static/nonfreezing hypothermic preservation of rat hearts in a preservative solution with added AFGP based on our hypothesis that AFGP would be useful as a cryoprotectant in a static hypothermic preservation solution used in the hypothermic preservation of cardiomyocytes.

\section{Methods}

The methods for removing rat hearts, reperfusion experiments using the Langendorff apparatus, and for measuring cardiac function are described below and were the same as reported by us earlier for an isolated rat heart model (Kato et al. 2012). Briefly, we used adult Wistar male rats (age: 10-12 weeks, body weight: 250-300 g; Japan SCL, Shizuoka, Japan). Experimental animals were handled in accordance with the "Guide for the Care and Use of Laboratory Animals: Eighth Edition" of the Institute for Laboratory Animal Research (2010). Approval was obtained from the Institute for Experimental Animals, Kanazawa University Advanced
Science Research Center (approval no. AP-153592). Animals were anesthetized initially by making them inhale $4 \%-5 \%$ isoflurane (Wako Pure Chemical Industries, Osaka, Japan), which was then switched to maintenance levels of $1.5 \%-3 \%$. The anterior region of the animals' necks, and the tracheas were incised longitudinally. After tracheal intubation, the animals were placed on mechanical ventilators (initial settings: $1 \mathrm{~Hz}$; tidal volume, $3.2 \mathrm{ml}$; and fraction of inspired oxygen, 0.21 ). Laparotomy and thoracotomy were performed, and the heart, inferior vena cava, superior vena cava, and ascending aorta were exposed. Five hundred units of heparin (Mochida Pharmaceutical, Tokyo, Japan) were injected via the inferior vena cava, and both the inferior and superior vena cava were dissected. The ascending aorta was also dissected and a 2-mm cannula for administration of the cardioplegia solution was connected (Medtronic, Minneapolis, MN, USA). The cardioplegia solution $\left(4{ }^{\circ} \mathrm{C}\right.$; total, $50 \mathrm{ml}$; injection rate, $5 \mathrm{ml} / \mathrm{min}$ ) was administered via this cannula, and the heart was stopped. The heart was surgically extracted and immersed in one of the cardioplegia solutions described below. In the control group, the University of Wisconsin (UW) cardioplegia solution was used (Viaspan [in g/l: pentafraction, 50; lactobionic acid, 35.83; potassium phosphate monobasic, 3.4; magnesium sulfate heptahydrate, 1.23; raffinose pentahydrate, 17.83; adenosine, 1.34; allopurinol, 0.136; total glutathione, 0.922; potassium hydroxide, 5.61; pH 7.4]; Astellas Pharma, Tokyo, Japan). In the AFGP group, the cardioplegia solution used was the UW solution containing $500 \mu \mathrm{g} / \mathrm{ml}$ AFGP. The preservative immersion solutions used were the same as the cardioplegia solutions; that is, the UW solution in the control group and the UW solution with AFGP $500 \mu \mathrm{g} / \mathrm{ml}$ in the AFGP group.

$A F G P$

The AFGP used in these experiments was extracted from fish in the cod family (Nichirei Foods, Chiba, Japan). AFGP, which is a solid, is a highly refined product guaranteed to have a purity of at least $90 \%$. It was dissolved in the UW solution to $500 \mu \mathrm{g} / \mathrm{ml}$, and this solution was allowed to stand for $2 \mathrm{~h}$ to remove bubbles before use.

\section{Experimental groups}

Cardioplegia was performed under two conditions. In the control group $(n=6)$, for which the 
conventional method was used, immersion preservation was performed in the UW solution. In the AFGP group $(n=6)$, immersion preservation was performed in the UW solution + AFGP $500 \mu \mathrm{g} / \mathrm{ml}$. In both the groups, immersion was carried out at $4{ }^{\circ} \mathrm{C}$ for $24 \mathrm{~h}$.

After preservation for $24 \mathrm{~h}$, hearts were connected to a Langendorff apparatus and reperfusion, consisting of retrograde perfusion from the ascending aorta to the coronary arteries, was performed (Fig. 1).
The perfusion solution was infused into the coronary arteries at a pressure of $75 \mathrm{mmHg}$ for $120 \mathrm{~min}$. The perfusion was performed using the Krebs-Henseleit solution (in $\mathrm{mM}$ : $\mathrm{NaCl}, 118 ; \mathrm{KCl}, 4.7 ; \mathrm{MgSO}_{4} \cdot 7 \mathrm{H}_{2} \mathrm{O}, 1.2$; $\mathrm{CaCl}_{2} \cdot 2 \mathrm{H}_{2} \mathrm{O}, 2.5 ; \mathrm{NaHCO}_{3}, 25$; glucose, 11.0; $\mathrm{KH}_{2} \mathrm{PO}_{4}$, 1.2; $\mathrm{pH}=7.6$ ), which was made at our facility. This solution was heated to $37.0{ }^{\circ} \mathrm{C}$ and buffered with $95 \%$ oxygen and $5 \%$ carbon dioxide.

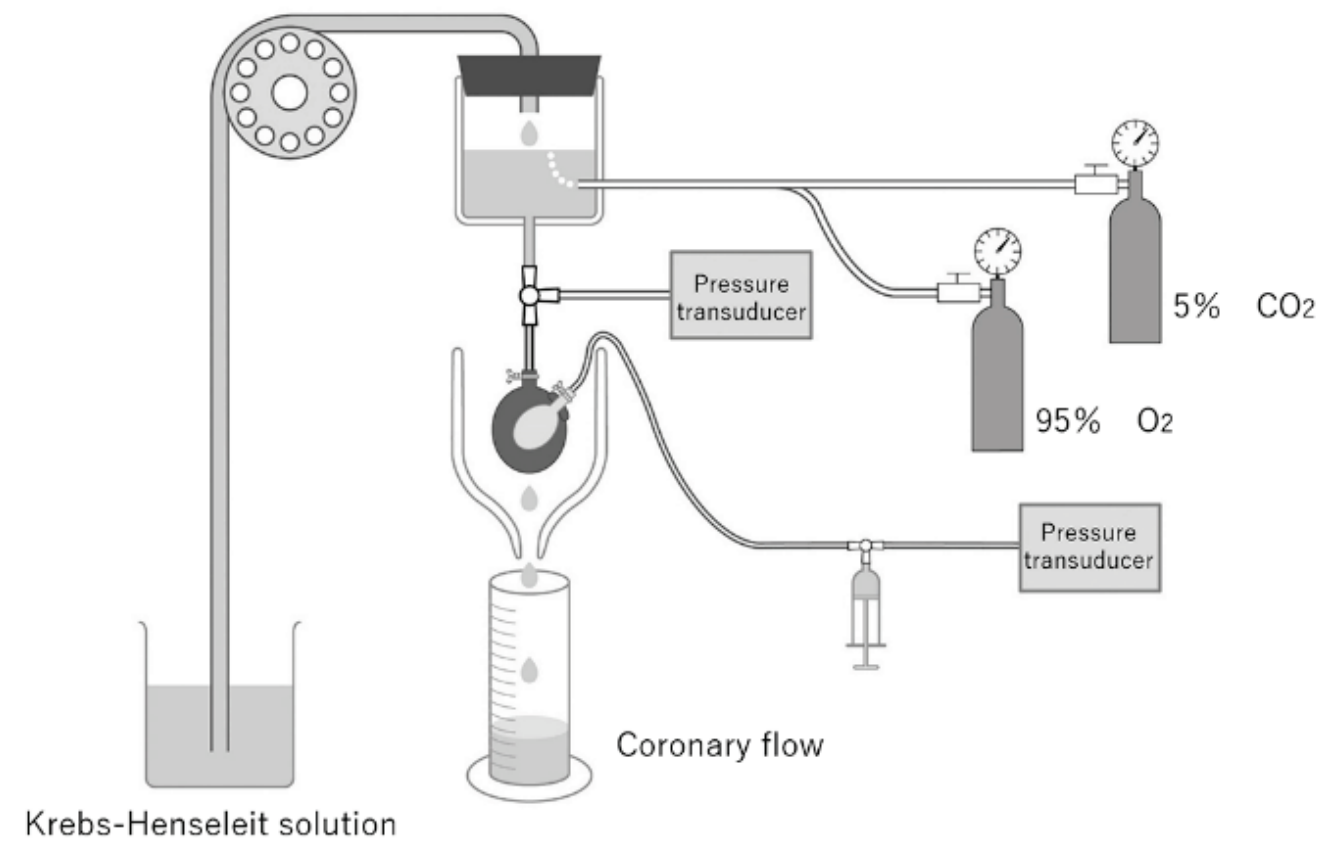

Fig. 1. Reperfusion experiments using the Langendorff apparatus. The perfusion solution was infused into the coronary arteries at a pressure of $75 \mathrm{mmHg}$ for $120 \mathrm{~min}$. Krebs-Henseleit solution buffered with $95 \%$ oxygen and $5 \%$ carbon dioxide. Left ventricular pressure was measured by connecting a pressure transducer to a $3 \mathrm{Fr}$ latex balloon catheter, which was inserted into the left ventricle via the left atrium.

\section{Functional measurements in the graft}

Cardiac function measurements performed in conjunction with the reperfusion experiments were as follows: Left ventricular pressure was measured by connecting a pressure transducer (VO1706TSPL03; Edwards Life Science, Irvine, CA, USA) to a 3Fr latex balloon catheter (Unique Medical, Komae-shi, Tokyo, Japan) filled with physiological saline, which was inserted into the left ventricle via the left atrium. The latex balloon catheter was then inflated to a diastolic pressure of $8 \mathrm{mmHg}$. Pressure changes were analyzed using LabChart7 version 7.3.7 (AD Instruments, Bella Vista, New South Wales, Australia). At 30, 60, 90, and $120 \mathrm{~min}$ after the start of reperfusion, heart rate (HR), coronary flow $(\mathrm{CF})$, max $\mathrm{dP} / \mathrm{dt}$ (rate of pressure change), and $\mathrm{min} \mathrm{dP} / \mathrm{dt}$ (negative rate of pressure change) were measured. CF was calculated on the basis of the amount of coronary perfusion solution used. Max $\mathrm{dP} / \mathrm{dt}$ indicates cardiac contractile force and $\mathrm{min} \mathrm{dP} / \mathrm{dt}$ indicates cardiac diastolic force (Kato et al. 2012). During cardiac function measurements, pacing was not used to maintain the heartbeat; instead, the hearts were allowed to beat spontaneously.

\section{Tissue ATP levels}

The extraction of ATP was performed according to the method reported previously (Prokudina et al. 2019). After $120 \mathrm{~min}$ of reperfusion, approximately $0.1 \mathrm{~g}$ of the myocardium was removed surgically from the beating hearts. This portion of the myocardium was snap frozen and homogenized in liquid nitrogen $\left(-196{ }^{\circ} \mathrm{C}\right)$. The weight of the frozen myocardium sample was measured and $1 \mathrm{ml}$ of protein removal solution (perchloric acid, $0.6 \mathrm{~N}$ ) per $0.1 \mathrm{~g}$ of myocardium tissue was added. The homogenate was centrifuged at $4{ }^{\circ} \mathrm{C} / 3,000 \mathrm{~g}$ for $10 \mathrm{~min}$. The supernatant was then 
neutralized in a triethanolamine/potassium carbonate solution and preserved at $-80 \quad{ }^{\circ} \mathrm{C}$ until ATP measurements were taken. The concentration of ATP was measured by absorption spectroscopy (Lucifell 250 Plus; Kikkoman, Tokyo, Japan). The ATP levels are expressed in $\mu$ mole per dried tissue weight of left ventricular tissue. To reduce ATP consumption to a minimum during sample preparation, the collection site was the left ventricular apex, which allowed samples to be collected quickly and easily while the heart was beating.

\section{Tissue water content (TWC)}

After $120 \mathrm{~min}$ of reperfusion, the heart tissue remaining after removal of the portion used for ATP extraction was air-dried over a $72 \mathrm{~h}$ period in the laboratory, where the environment was controlled at a room temperature of $23{ }^{\circ} \mathrm{C}$ and humidity of $30 \%$. The percentage TWC was calculated using the following formula: $\mathrm{TWC}=(\mathrm{WW}-\mathrm{DW}) / \mathrm{WW} \times 100$, where $\mathrm{WW}$ was the "wet tissue weight" (g) and DW was the "dry tissue weight" $(\mathrm{g})$.

\section{Statistical analyses}

Data are presented as means \pm standard deviation and median (interquartile range) values, and are plotted on graphs. The statistical software used was EZR version 1.38 (Kanda et al. 2013). The control and AFGP groups were compared for the following parameters: HR, $\mathrm{CF}, \max \mathrm{dP} / \mathrm{dt}$, min $\mathrm{dP} / \mathrm{dt}$, tissue ATP level, and TWC. All measured values were determined to be either in normal or non-normal distributions using the ShapiroWilk normality test. When sampling data for both the control and AFGP groups were normally distributed, Student's $t$-test was performed. In cases where data were non-normally distributed, the Mann-Whitney U test was applied. Significance was set at a p-value $<0.05$.

\section{Results}

\section{Heart rate}

Comparisons of the control versus AFGP group HR indicated the following values at $30,60,90$, and 120 min: $80.7 \pm 1.4$ vs. $80.0 \pm 2.5 / \mathrm{min}(\mathrm{p}=0.55), 78.7 \pm 37.6$ vs. $134 \pm 24.3 / \mathrm{min} \quad(p=0.013), 98.5 \pm 38.4$ vs. $167 \pm 33.1 / \mathrm{min}$ $(\mathrm{p}=0.0079)$, and $103 \pm 46.7$ vs. $174 \pm 33.0 / \mathrm{min}(\mathrm{p}=0.012)$, respectively (Fig. 2). Thus, at 60, 90, and $120 \mathrm{~min}$ after the start of the reperfusion experiments, the AFGP group had significantly higher autonomous HRs than the control group.

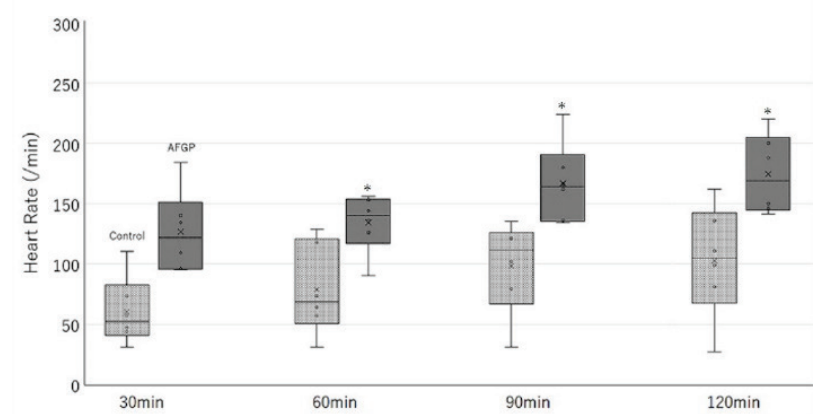

Fig. 2. Heart rate during reperfusion. The AFGP group had significantly higher HRs than the control group at 60,90 , and 120 min after the start of the reperfusion experiments $\left({ }^{*} p<0.05\right)$.

$C F$

Comparisons of the control versus AFGP group $\mathrm{CF}$ indicated the following values at 30, 60, 90, and $120 \mathrm{~min}: 2.47 \pm 1.93$ vs. $4.60 \pm 0.59 \mathrm{ml} / \mathrm{min} \quad(\mathrm{p}=0.028)$, $2.03 \pm 1.27$ vs. $4.87 \pm 0.39 \mathrm{ml} / \mathrm{min}(\mathrm{p}=0.0047), 2.92 \pm 1.44$ vs. $5.37 \pm 0.39 \mathrm{ml} / \mathrm{min}(\mathrm{p}=0.0024)$, and $3.50 \pm 1.83$ vs. $5.77 \pm 0.53 \mathrm{ml} / \mathrm{min}(\mathrm{p}=0.016)$, respectively (Fig. 3). Thus, at all the studied time points, the AFGP group had significantly higher CFs than the control group.

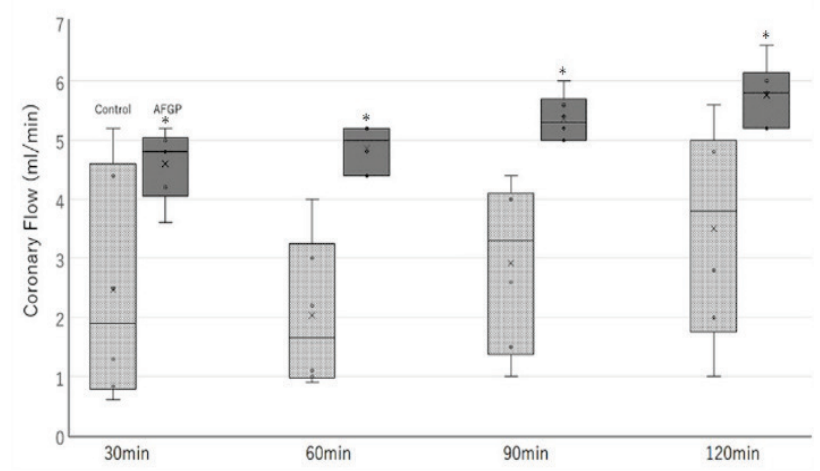

Fig. 3. Coronary flow during reperfution. The AFGP group had significantly higher CFs than the control group at all studied time points $\left({ }^{*} p<0.05\right)$.

$\max d P / d t$

Max dP/dt values of the control versus AFGP group at $30,60,90$, and $120 \mathrm{~min}$ were as follows: $165 \pm 128$ vs. $463 \pm 319 \mathrm{mmHg} / \mathrm{s} \quad(\mathrm{p}=0.060), 187 \pm 91.1$ vs. $397 \pm 300 \mathrm{mmHg} / \mathrm{s} \quad(\mathrm{p}=0.13), \quad 127 \pm 66.6$ vs. $488 \pm 236$ $\mathrm{mmHg} / \mathrm{s}(\mathrm{p}=0.0048)$, and $177 \pm 129$ vs. $521 \pm 370 \mathrm{mmHg} / \mathrm{s}$ $(p=0.056)$, respectively (Fig. 4A). At 90 min after the start of reperfusion, the $\max \mathrm{dP} / \mathrm{dt}$ was significantly higher in the AFGP group than in the control group. At other time points, the contractile force of the preserved hearts in the AFGP group was not significantly higher. 
$\min d P / d t$

Comparisons of the control versus AFGP group for $\mathrm{min} \mathrm{dP} / \mathrm{dt}$ at $30,60,90$, and $120 \mathrm{~min}$ were as follows: $170 \pm 143$ vs. $435 \pm 298 \mathrm{mmHg} / \mathrm{s} \quad(\mathrm{p}=0.078), 177 \pm 87.3$ vs. $350 \pm 232 \quad(\mathrm{p}=0.12), \quad 127 \pm 65.6$ vs. $461 \pm 235 \mathrm{mmHg} / \mathrm{s}$ $(\mathrm{p}=0.0072)$, and $159 \pm 90.6$ vs. $532 \pm 384 \mathrm{mmHg} / \mathrm{s}$ $(p=0.044)$, respectively (Fig. 4B). At 90 and $120 \mathrm{~min}$ after the start of reperfusion, the $\mathrm{min} \mathrm{dP} / \mathrm{dt}$ in the AFGP group was significantly higher than that in the control group. At other time points, the diastolic force of the preserved hearts in the AFGP group was not significantly higher.

A
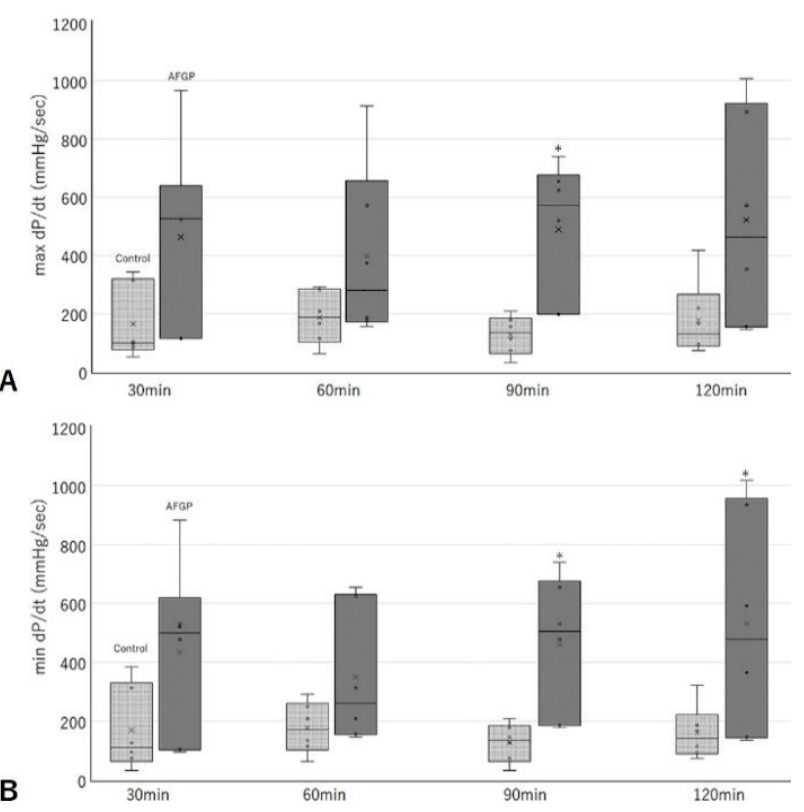

Fig. 4. A) $\max d P / d t$ (rate of pressure change) flow during reperfution. The AFGP group had significantly higher max $\mathrm{dP} / \mathrm{dt}$ than the control group at $90 \mathrm{~min}$ after the start of the reperfusion experiments $\left({ }^{*} p<0.05\right)$. B) $\mathrm{min} d P / d t$ (negative rate of pressure change) flow during reperfution. The AFGP group had significantly higher min $\mathrm{dP} / \mathrm{dt}$ than the control group at 90 and $120 \mathrm{~min}$ after the start of the reperfusion experiments $(* \mathrm{p}<0.05)$.

\section{$T W C$}

The TWC was $80.7 \% \pm 1.4 \%$ vs. $80.0 \% \pm 2.5 \%$ $(\mathrm{p}=0.55)$ for the control and AFGP groups, respectively (Fig. 5A). This indicated that there was no significant difference in the myocardial edema of post-reperfusion preserved hearts.

\section{ATP levels}

Tissue ATP levels were $1.10 \pm 0.30$ vs. $4.28 \pm$ $2.34 \mu \mathrm{mol} / \mathrm{g}$ (dry weight) $(\mathrm{p}=0.0079)$ for the control and AFGP groups, respectively (Fig. 5B). This indicated that the preserved hearts in the AFGP group maintained higher levels of ATP in their tissues compared to the control group.
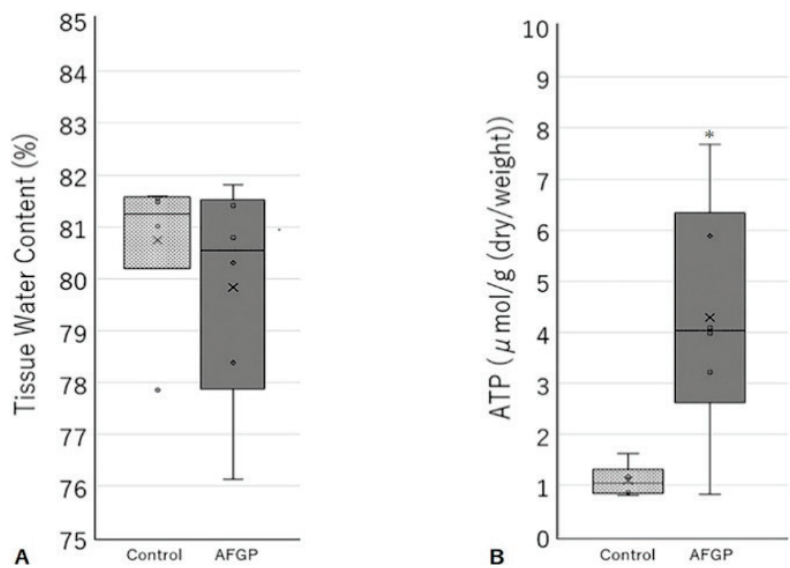

Fig. 5. A) Tissue water content (TWC) after $120 \mathrm{~min}$ of reperfusion. TWC did not differ significantly between two groups. B) Tissue adenosine triphosphate (ATP) levels after $120 \mathrm{~min}$ of reperfusion. The AFGP group maintained higher levels of ATP in their tissues compared to the control group $(* \mathrm{p}<0.05)$.

\section{Discussion}

In this study, we added purified AFGP to the immersion solution used for cryopreserving rat hearts at $4{ }^{\circ} \mathrm{C}$ for $24 \mathrm{~h}$. In our reperfusion experiments conducted on the preserved hearts, we measured $\mathrm{HR}, \mathrm{CF}$, $\max \mathrm{dP} / \mathrm{dt}$, and $\min \mathrm{dP} / \mathrm{dt}$ as indicators of their hemodynamic functions. The $\mathrm{HR}$ at all-time points after $30 \mathrm{~min}$ following the start of reperfusion $(60,90,120 \mathrm{~min})$; $\mathrm{CF}$ at all-time points following the start of reperfusion; and both $\max \mathrm{dP} / \mathrm{dt}$ and $\mathrm{min} \mathrm{dP} / \mathrm{dt}$ at 30,90 , and $120 \mathrm{~min}$ following the start of reperfusion were higher in the AFGP group than in the control group. These data showed that the preserved hearts treated with AFGP maintained better hemodynamic function than those in the control group. We also measured tissue ATP levels at the end of reperfusion to assess metabolic function. The results showed higher values in the AFGP group, indicating that AFGP helped maintain metabolic functions.

In recent years, it has become possible to prolong the ischemia time through the perfusion of preservation solution into solid organs, such as the heart and kidney. However, specialized circuits and apparatus are required to maintain electrolytes, oxygen saturation, and perfusion pressure of the perfusion solution (Michel et al. 2015). Thus, static hypothermic preservation has become the main method for preserving hearts owing to 
its ease and low cost. Because the metabolic processes of preserved organs are reduced when they are stored using static hypothermic preservation, this method is useful in preservation at low temperatures (Belzer et al. 1988). However, electrolyte imbalances and cell edema are limitations associated with static hypothermic preservation (Rubinsky et al. 2003).

Currently, static hypothermic preservation of hearts for use in heart transplantation is generally performed at $4{ }^{\circ} \mathrm{C}$, and the safe time limit is between 4 and $6 \mathrm{~h}$ (Jahania et al. 1999, George et al. 2011). Attempts have been made to develop stable hypothermic preservation methods that resolve these problems, such as mixing cryoprotectants like glycerol into the immersion solution (Yang et al. 1993, Sakaguchi et al. 1998). In addition, although the development of a variety of organ preservative solutions with adjusted osmotic pressure and electrolytes is ongoing, these have yet to achieve an extension of the ischemic time close to that of static hypothermic preservation in heart transplantation. Thus, we believe that the discovery of a new cryoprotectant that is useful in hypothermic preservation would help increase the time-related safety limit of static hypothermic preservation.

Biological substances identified in Nototheniidae fish, which are native to cold regions of the world, lower the freezing point of body fluids and restrict the growth of ice crystals (DeVries and Wohlschlag 1969). One of these biological substances that has been identified is AFP. Fish-derived AFPs are classified as AFP I-IV and AFGP. Each AFGP consists of a number of repeating tripeptide units of (Ala-AlaThr)n, with minor sequence variations. The glycoproteins isolated from the Nototheniidae fish have been further classified as AFGP1-8 on the basis of their relative rates of electrophoretic migration. The number of tripeptide repetitions varies, and the molecular weight of AFGP is between 2600 and $33000 \mathrm{Da}$ (Harding et al. 2003). In addition to their ability to lower the freezing point, AFPs protect cells through the transfer of electrolytes via the cell membrane and prevent cell edema by forming a protective layer around the cell membrane when cells are preserved in hypothermic environments (Rubinsky et al. 1990, Rubinsky et al. 1992). Tomczak et al. proposed that AFGPs may form a monolayer covering the membrane surface, thereby, reducing the leakage of ions across the membrane as it is cooled through its thermal transition temperature (Tomczak et al. 2002).

In recent years, hypothermic preservation experiments using pancreas cells, sperm, and oocytes have focused on the cell-protective properties of AFPs, and it has been reported that they are useful as alternative cryoprotectants to dimethyl sulfoxide and glycerol (Matsumoto et al. 2006, Qadeer et al. 2015, Rubinsky et al. 1991, Kamijima et al. 2013, Prathalingam et al. 2006). Recent studies have focused on practical applications of AFPs as substrate additives for the hypothermic preservation of solid organs. AFPI has been used as a substrate additive in the hypothermic preservation of livers (Soltys et al. 2001). In addition, experiments using AFPI and AFPIII as cryoprotectants for the hypothermic preservation of hearts have reported that cardiac functions following reperfusion are preserved satisfactorily, and that structures of the myocardium and mitochondria remain intact (Amir et al. 2004, Amir et al. 2005). However, in all the studies indicating that AFPs are useful in the hypothermic preservation of solid organs, AFP has been used; thus, it remains unknown whether AFGP is useful in the preservation of solid organs (Wang et al. 1994, Mugnano et al. 1995).

In recent years, studies on the large-scale refinement of AFPs have been performed, which have led to practical applications of these compounds (Nishimiya et al. 2008). The focus of research has expanded to include the high-purity refinement of AFGP (Burcham et al. 1986). In the present study, we focused on AFGP and carried out experiments on the static/nonfreezing hypothermic preservation of rat hearts in preservative solution with added AFGP. This was based on our hypothesis that AFGP would be useful as a cryoprotectant in the immersion solution used in the hypothermic preservation of solid organs by preserving the hemodynamic and metabolic functions of the heart. The results showed that post-reperfusion tissue ATP levels were significantly higher in the AFGP group than in the control group. There was a correlation between cardiac function and ATP levels in the myocardial tissue; the latter is a good indicator of the status of preserved hearts (Stringham et al. 1992, Pernot et al. 1983, Sakaguchi et al. 1996). Specifically, high tissue ATP levels indicate an excellent status of the cardiomyocytes, even in terms of metabolic function.

We measured TWC as an indicator of myocardial edema during static hypothermic preservation as it allows an assessment of damage to the preserved heart (Kato et al. 2012). We found that, in contrast to the satisfactory hemodynamic and metabolic functions observed in preserved hearts in the AFGP group, TWC in 
the AFGP group was low, although not significantly. However, research has shown that myocardial edema may increase despite good cardiac functions observed in post-preservation reperfusion experiments; this is believed to indicate the complexity of the action of hydrostatic pressure on the myocardium (Zhang et al. 2010). Because we found that CF was significantly higher in the AFGP group than in the control group, it is possible that higher amounts of perfusion solution penetrated cardiomyocytes and stroma in the AFGP group via the coronary arterial endothelia. This, in turn, may have increased the hydrostatic pressure in those locations. Furthermore, it is conceivable that in cells and organoids in preservation experiments wherein AFGP was used as a substrate additive, AFGP may have been localized to cell membrane surfaces that were in contact with the immersion solution (Tomczak et al. 2002, Huelsz-Prince et al. 2019). Although we did not assess the localization of AFGP in this study, we believe that it may act primarily on the coronary artery endothelium and endocardial cells of the preserved heart that are in direct contact with the immersion solution. The degree of edema observed in a large portion of cardiomyocytes that had no direct contact with the immersion solution was the same in preserved hearts both in the control and AFGP groups. This might explain the similarity between the control and AFGP groups in terms of TWC.

Some studies on the use of AFGP to preserve cells have used approximately $10 \mathrm{mg} / \mathrm{ml}$ of the protein (Sakaguchi et al. 1998, Kamijima et al. 2013, HuelszPrince et al. 2019, Hirano et al. 2008). However, AFGP increases the viscosity of solutions in a concentrationdependent $(1-10 \mathrm{mg} / \mathrm{ml}$ ) manner (Eto and Rubinsky 1993). When dissolving AFGP in the UW solution at the preliminary experiment stage, the solution was highly viscous and it was difficult to remove bubbles. In addition, the high viscosity of the UW solution itself might explain endovascular endothelial damage during coronary perfusion (Mankad et al. 1992). From the perspective of the coronary vascular bed, we believe it is important to prevent increased viscosity of the immersion solution. One study that reported the use of low AFGP concentrations found that $500 \mu \mathrm{g} / \mathrm{ml}$ was effective in protecting pancreatic cells during cryopreservation (Matsumoto et al. 2006). Therefore, we used a relatively low concentration of $500 \mu \mathrm{g} / \mathrm{ml}$ in all our experiments.

Our study had some limitations. First, the model was in vitro with preserved hearts connected to a Langendorff coronary perfusion apparatus and the use of Krebs-Henseleit perfusion solution. Second, the safety of using AFGP during the perfusion of blood containing white blood cells and cytokines is unknown. This warrants the need for additional studies to verify that AFGP can be used safely in the preservation of human organs. Third, an in vivo model using allogenic transplantation in rats must be performed to investigate the usefulness of AFGP. Finally, because we did not verify the localization of AFGP and the sites where it is effective, the need to further study the importance of AFGP localization remains. Overall, there have been few studies on cryopreservation using AFGP. Thus, the optimum conditions for its use, including the optimum concentration and temperature range, need to be determined and established.

This is an innovative report applying AFGP to the preservation of a solid organ. In this study, we used AFGP as a substrate additive in the static/nonfreezing hypothermic preservation of rat hearts. In the AFGP group, hemodynamic and metabolic functions were better maintained in the preserved hearts than in the control group. The results are expected to extend the allowable ischemic time of organ transplantation and permit the transport of transplant organs over long distances easily.

\section{Conflict of Interest}

There is no conflict of interest.

\section{Acknowledgements}

Shintaro Takago, Isao Matsumoto, and Hiroki Kato received AFGP from Nichirei Foods Inc. (Chiba, Japan). This work was supported by Japanese Society for the Promotion of Science, Grant/Award Number: JSPS KAKENHI Grant Number JP19K18174.

\section{References}

AMIR G, HOROWITZ L, RUBINSKY B, YOUSIF BS, LAVEE J, SMOLINSKY AK: Subzero nonfreezing cryopresevation of rat hearts using antifreeze protein I and antifreeze protein III. Cryobiology 48: 273-282, 2004. https://doi.org/10.1016/j.cryobiol.2004.02.009 
AMIR G, RUBINSKY B, BASHEER SY, HOROWITZ L, JONATHAN L, FEINBERG MS, SMOLINSKY AK, LAVEE J: Improved viability and reduced apoptosis in sub-zero 21-hour preservation of transplanted rat hearts using anti-freeze proteins. J Heart and Lung Transplant 24: 1915-1929, 2005. https://doi.org/10.1016/j.healun.2004.11.003

BELZER FO, SOUTHARD JH: Principles of solid-organ preservation by cold storage. Transplantation 45: 673-676, 1988. https://doi.org/10.1097/00007890-198804000-00001

BURCHAM TS, OSUGA DT, RAO BN, BUSH CA, FEENEY RE: Purification and primary sequences of the major arginine-containing antifreeze glycopeptides from the fish eeginus gracilis. J Biol Chem 261: 6384-6389, 1986.

DEVRIES AL, WOHLSCHLAG DE: Freezing resistance in some Antarctic fishes. Science 163: 1073-1075, 1969. https://doi.org/10.1126/science.163.3871.1073

ETO TK, RUBINSKY B: Antifreeze glycoproteins increase solution viscosity. Biochem Biophys Res Commun 197: 927-931, 1993. https://doi.org/10.1006/bbrc.1993.2568

GEORGE TJ, ARNAOUTAKIS GJ, BAUMGARTNER WA, SHAH AS, CONTE JV: Organ storage with University of Wisconsin solution is associated with improved outcomes after orthotopic heart transplantation. J Heart Lung Transplant 30: 1033-1043, 2011. https://doi.org/10.1016/j.healun.2011.05.005

HARDING MM, ANDERBERG PI, HAYMET AD: 'Antifreeze' glycoproteins from polar fish. Eur J Biochem 270: 1381-1392, 2003. https://doi.org/10.1046/j.1432-1033.2003.03488.x

HIRANO Y, NISHIMIYA Y, MATSUMOTO S, MATSUSHITA M, TODO S, MIURA A, KOMATSU Y, TSUDA S: Hypothermic preservation effect on mammalian cells of type III antifreeze proteins from notched-fin eelpout. Cryobiology 57: 46-51, 2008. https://doi.org/10.1016/j.cryobiol.2008.05.006

HUELSZ-PRINCE G, DEVRIES AL, BAKKER HJ, VAN ZON JS, MEISTER K: Effect of antifreeze glycoproteins on organoid survival during and after hypothermic storage. Biomolecules 9: E110, 2019. https://doi.org/10.3390/biom9030110

JAHANIA MS, SANCHEZ JA, NARAYAN P, LASLEY RD, MENTZER RM JR: Heart preservation for transplantation: principles and strategies. Ann Thorac Surg 68: 1983-1987, 1999.

KATO H, TOMITA S, YAMAGUCHI S, OHTAKE H, WATANABE G: Subzero 24-hr nonfreezing rat heart preservation: a novel preservation method in a variable magnetic field. Transplantation 94: 473-477, 2012. https://doi.org/10.1097/TP.0b013e3182637054

KAMIJIMA T, SAKASHITA M, MIURA A, NISHIMIYA Y, TSUDA S: Antifreeze protein prolongs the life-time of insulinoma cells during hypothermic preservation. PLoS One 8: e73643, 2013. https://doi.org/10.1371/journal.pone.0073643

KANDA Y: Investigation of the freely available easy-to-use software 'EZR' for medical statistics. Bone Marrow Transplant 48: 452-458, 2013. https://doi.org/10.1038/bmt.2012.244

MANKAD P, SLAVIK Z, YACOUB M: Endothelial dysfunction caused by University of Wisconsin preservation solution in the rat heart. The importance of temperature. J Thorac Cardiovasc Surg 104: 1618-1624, 1992. https://doi.org/10.1016/S0022-5223(19)33892-9

MATSUMOTO S, MATSUSITA M, MORITA T, KAMACHI H, TSUKIYAMA S, FURUKAWA Y, KOSHIDA S, TACHIBANA Y, NISHIMURA S, TODO S: Effects of synthetic antifreeze glycoprotein analogue on islet cell survival and function during cryopreservation. Cryobiology 52: 90-98, 2006. https://doi.org/10.1016/j.cryobiol.2005.10.010

MICHEL SG, LA MURAGLIA GM 2ND, MADARIAGA ML, TITUS JS, SELIG MK, FARKASH EA, ALLAN JS, ANDERSON LM, MADSEN JC: Twelve-hour hypothermic machine perfusion for donor heart preservation leads to improved ultrastructural characteristics compared to conventional cold storage. Ann Transplant 20: 461-468, 2015. https://doi.org/10.12659/AOT.893784

MUGNANO JA, WANG T, LAYNE JR JR, DEVRIES AL, LEE RE JR: Antifreeze glycoproteins promote intracellular freezing of rat cardiomyocytes at high subzero temperatures. Am J Physiol 269: 474-479, 1995. https://doi.org/10.1152/aipregu.1995.269.2.R474

NISHIMIYA Y, MIE Y, HIRANO Y, KONDO H, MIMURA A, TSUDA S: Mass preparation and technological development of an antifreeze protein. Synthesiology 1: 7-14, 2008. https://doi.org/10.5571/syntheng.1.7 
PERNOT AC, INGWALL JS, MENASCHE P, GROUSSET C, BERCOT M, PIWNICA A, FOSSEL ET: Evaluation of high energy phosphate metabolism during cardioplegic arrest and reperfusion: a phosphorus-31 nuclear magnetic resonance study. Circulation 67: 1296-1303, 1983. https://doi.org/10.1161/01.CIR.67.6.1296

PRATHALINGAM NS, HOLT WV, REVELL SG, MIRCZUK S, FLECK RA, WATSON PF: Impact of antifreeze proteins and antifreeze glycoproteins on bovine sperm during freeze-thaw. Theriogenology 66: 1894-1900, 2006. https://doi.org/10.1016/j.theriogenology.2006.04.041

PROKUDINA ES, NARYZHNAYA NV, MUKHOMEDZYANOV AV, GORBUNOV AS, ZHANG Y, JAGGI AS, TSIBULNIKOV SY, NESTEROV EA, LISHMANOV YB, SULEIMAN MS, OELTGEN PR, MASLOV LN: Effect of chronic continuous normobaric hypoxia on functional state of cardiac mitochondria and tolerance of isolated rat heart to ischemia and reperfusion: Role of $\mu$ and $\delta 2$ opioid receptors. Physiol Res 68: 909-920, 2019. https://doi.org/10.3938/NPSM.68.909

QADEER S, KHAN MA, ANSARI MS, RAKHA BA, EJAZ R, IQBAL R, YOUNIS M, ULLAH N, DEVRIES AL, AKHTER S: Efficiency of antifreeze glycoproteins for cryopreservation of Nili-Ravi (Bubalus bubalis) buffalo bull sperm. Anim Reprod Sci 157: 56-62, 2015. https://doi.org/10.1016/j.anireprosci.2015.03.015

RUBINSKY, B: Principles of Low Temperature Cell Preservation. Heart Fail Rev 8: 277-284, 2003. https://doi.org/10.1023/A:1024734003814

RUBINSKY B, ARAV A, FLETCHER GL: Hypothermic protection - a fundamental property of "antifreeze" proteins. Biochem Biophys Res Commun 180: 566-571, 1991. https://doi.org/10.1016/S0006-291X(05)81102-7

RUBINSKY B, ARAV A, MATTIOLI M, DEVRIES AL: The effect of antifreeze glycopeptides on membrane potential changes at hypothermic temperatures. Biochem Biophys Res Commun 173: 1369-1374, 1990. https://doi.org/10.1016/S0006-291X(05)80939-8

RUBINSKY B, MATTIOLI M, ARAV A, BARBONI B, FLETCHER GL: Inhibition of $\mathrm{Ca}^{2+}$ and $\mathrm{K}^{+}$currents by "antifreeze" proteins. Am J Physiol 262: 542-545, 1992. https://doi.org/10.1152/ajpregu.1992.262.3.R542

SAKAGUCHI H, KITAMURA S, KAWACHI K, KOBAYASHI S, YOSHIDA Y, NIWAYA K, GOJO S: Preservation of myocardial function and metabolism at subzero nonfreezing temperature storage of the heart. J Heart Lung Transplant 15: 1101-1107, 1996.

SAKAGUCHI H, TANIGUCHI S, KOBAYASHI S, TSUJI T, ABE T, KITAMURA S: Subzero nonfreezing storage (-1 degree C) of the heart with University of Wisconsin solution and 2,3-butanediol. Transplant Proc 30: 58-59, 1998. https://doi.org/10.1016/S0041-1345(97)01178-0

SOLTYS KA, BATTA AK, KONERU B: Successful nonfreezing, subzero preservation of rat liver with 2,3-butanediol and type I antifreeze protein. J Surg Res 96: 30-34, 2001. https://doi.org/10.1006/jsre.2000.6053

STEHLIK J, EDWARDS LB, KUCHERYAVAYA AY, BENDEN C, CHRISTIE JD, DOBBELS F, KIRK R, RAHMEL AO, HERTZ MI: The Registry of the International Society for Heart and Lung Transplantation: twenty-eighth adult heart transplant report-2011. J Heart Lung Transplant 30: 1078-1094, 2011. https://doi.org/10.1016/j.healun.2011.08.003

STRINGHAM JC, SOUTHARD JH, HEGGE J, TRIEMSTRA L, FIELDS BL, BELZER FO: Limitations of heart preservation by cold storage. Transplantation 53: 287-294,1992. https://doi.org/10.1097/00007890-199202010$\underline{00007}$

TOMCZAK MM, HINCHA DK, ESTRADA SD, WOLKERS WF, CROWE LM, FEENEY RE, TABLIN F, CROWE JH: A mechanism for stabilization of membranes at low temperatures by an antifreeze protein. Biophys $\mathrm{J}$ 82: 874-881, 2002. https://doi.org/10.1016/S0006-3495(02)75449-0

WANG T, ZHU Q, YANG X, LAYNE JR JR, DEVRIES AL: Antifreeze glycoproteins from antarctic notothenioid fishes fail to protect the rat cardiac explant during hypothermic and freezing preservation. Cryobiology 31: 185-192, 1994. https://doi.org/10.1006/cryo.1994.1022

YANG X, ZHU Q, LAYNE JR JR, CLAYDON M, HICKS GL JR, WANG T: Subzero nonfreezing storage of the mammalian cardiac explant. I. Methanol, ethanol, ethylene glycol, and propylene glycol as colligative cryoprotectants. Cryobiology 30: 366-375, 1993. https://doi.org/10.1006/cryo.1993.1036 
ZHANG F, MO A, WEN Z, ZHOU Y, LIANG S, LIN H: Continuous perfusion of donor hearts with oxygenated blood cardioplegia improves graft function. Transpl Int 23: 1164-1170, 2010. https://oi.org/10.1111/j.14322277.2010.01112.x 